Research and Development in the province has now reached the stage where input from the Chief Executive Officers of both industry and government is necessary. To ensure that research is given emphasis at the highest level, the New Brunswick Executive Forest Research Committee Inc. has been formed to promote effective research activities and expand their scope and substance to meet the forest management needs of the industry. This committee will:

1) advise forest research agencies of research priorities;

2) fund research in areas where current efforts are inadequate, and

3) assist NBFRAC in its task of planning and coordinating forest research efforts.

The Committee has employed a full time research coordinator to:

1) monitor and evaluate all forest research relevant to New Brunswick,

2) identify opportunities for cooperative projects to meet priorities, and

3) implement and manage Committee-sponsored research projects.

Industrial agencies represented on NBEFRC Inc. are Acadia -Forest Products Ltd., Boise Cascade Ltd., Consolidated-Bathurst Inc., Fraser Inc., Georgia Pacific Corp., J.D. Irving Ltd., Juniper Lumber Co. Ltd., MacMillan in Rothesay Ltd., Canadian International Paper Co., Northwood Pulp and Timber Ltd., St. Anne-Nackawic Pulp and Paper Co. Ltd. along with the New Brunswick Department of ป Natural Resources and the Canadian Forestry Service.

There are two principal agencies within the province which conduct research and development work in forestry problems. The Faculty of Forestry at the University of New Brunswick concentrates on hydrology and meteorology, ن고잉, silviculture, cone and seed technology, tree improveकnent, wood technology and operations research. The - 0 Maritimes Forest Centre specializes in budworm/forest inFeraction, ecology, effects of acid rain, tree and stand हु్의owth modelling, nursery and greenhouse technology, E eforestation, tree improvement, and other aspects of inten\&ive silviculture. The New Brunswick Department of Natural THesources and some forest industries conduct many Isurveys and trials on site preparation, plantation establishment and management, thinning, spacing, and fertilizing in natural stands, and selective cutting practices, besides being responsible for the forest inventory.

The present structure of the forest research advisory committees within New Brunswick will ensure that industry is continually aware of ongoing forest research and applicable results. Industry will also be able to influence the direction and execution of research so that the outcome will be appropriate to industry's new forest management responsibilities.

\section{Pulp and Paper Research Institute of Canada Industrial Assessment of Forestry Research}

Although the Pulp and Paper Research Institute of Canada is not involved in forestry research, it was requested by its Member Companies and by its Board of Directors in the fall of 1980 to assess the present status of forestry research in Canada from the viewpoint of the forest products industry. The results of this study are given in a three volume report edited by K.M. Thompson entitled "An Industrial Assessment of Forestry Research in Canada" dated October 1981.

On the advice of Prof. G.F. Weetman of the University of British Columbia who was retained as a consultant, the Institute approached eleven expert researchers in various areas of silviculture and forest protection research to prepare an assessment of the present status of research, and of the research needed in their respective areas. Areas selected were forest entomology, forest pathology, forest fire, natural regeneration, artificial reforestation, tree improvement, planting stock production, pre-commercial and commercial thinning, fertilization, mechanization of silvilculture and strategic studies. Additionally, Prof. G.F. Weetman prepared a discussion paper to assist the experts in addressing the question from an industrial viewpoint. Finally, the Maintaining Member Companies of the Institute were surveyed to obtain their views on the practice of silviculture.

Following preparation of the papers noted above, a twoday workshop was held at the Institute in Pointe Claire, Québec, on April 7 and 8, 1981. The workshop was attended by the experts themselves and by about 40 invited representatives from forest industry and provincial forest research establishments. The workshop was chaired by Dr. K.M. Thompson of the Institute, while Prof. G.F. Weetman and Mr. J.H. Cayford of the Canadian Forestry Service acted as rapporteurs. The purpose of the workshop was to provide a forum for discussion of the experts' recommendations. Each expert summarized his report, and this was followed by a discussion. After each area had been considered individually, a general discussion of all the research was held, followed by a summing up.

A number of studies of Canadian forestry research have been carried out in the past, while others are currently underway. It was the intention of the Institute that this assessment would complement others by focusing specifically on the research needs of industry in carrying out its new and increasing responsibilities for forest management.

A large number of topics of importance to the industry were identified in each of the areas of research considered. These should be the subject of further discussions between research foresters and their industry counteparts. It was clear that research in each area should be integrated with that done in the other areas, and with the practice of forest management in general. An improved system for providing the field forester with the latest usable information is also urgently needed. However, the greatest needs lie more in the managerial than the operational aspects of research. These are the needs for the industry to be continuously aware of what forestry research is being done, and the need for the industry to have an influence on the direction and execution of the research, so that the results will be appropriate to the industry's responsibilities for forest management.

A continuing review of forestry research needs, and assignment of priorities for specific needs, by the industry itself, is essential if the industry is to have the information required for intelligent forest management. In carrying out such a review, a number of factors must be allowed for. These include:

- the regional nature of many, but not all, of the specific forestry research needs;

- the need to consider the interactions within the entire forest system in both the practice of forest management, and the choice of the research to support this practice;

- the fact that each has different responsibilities and needs depending on the conditions of its tenure and the quality of its woodlands;

- and finally, the fact that implementation of research findings can be impeded by factors, such as cumbersome procedures for the registration of control agents, which are unrelated to research or operational needs.

K.M. Thompson

Pulp and Paper Research Institute of Canada 